\title{
(
}

\section{IMPACTO DA IMPLEMENTAÇÃO DAS BOAS PRÁTICAS DE FABRICAÇÃO EM INDÚSTRIA DE ALIMENTOS PARA ANIMAIS ${ }^{1}$}

\author{
Sandra Eldi de Oliveira Vargas \\ Consultora autônoma, e-mail: sandra-vargas@ig.com.br \\ Simone Moraes Raszl \\ SENAI/SC, e-mail: simone@sc.senai.br
}

\begin{abstract}
RESUMO: O estudo de caso foi realizado na Nutriara Alimentos Ltda, Paraná e teve como objetivo analisar o impacto da implementação das Boas Práticas de Fabricação (BPF) em uma indústria de alimentos para animais. $O$ período de análise dos dados compreendeu os anos de 2005 a 2008, no qual foram avaliados os percentuais de atendimento aos Roteiros de Inspeção das Instruções Normativas № 1/2007 e N 4/2007 do Ministério da Agricultura, Pecuária e Abastecimento do Brasil; o percentual de devolução de produtos não conformes e o percentual de reclamações no Serviço de Atendimento ao Cliente (SAC) referentes à qualidade dos produtos, antes e após a implementação das BPF. $O$ atendimento aos Roteiros de Inspeção foram crescentes com a implementação das BPF na empresa, pois à medida que as BPF foram implementadas ocorreu redução no percentual de devolução de produtos não conformes e redução das reclamações no SAC. Conclui-se que a implementação das BPF impactou positivamentena empresa.
\end{abstract}

Palavras-chave: Boas Práticas de Fabricação. Alimentos para animais. 


\section{INTRODUÇÃO}

Os animais de estimação desempenham um papel importante na qualidade de vida de seus proprietários. Até $80 \%$ dos cães são considerados como "membros" da família e $35 \%$ deles dormem na mesma cama que o dono (VERSIGNASSI et al., 2009). Como estes animais vivem em contato muito direto com seus proprietários, a alimentação é um fator muito importante, pois, associa-se ao alimento fornecido, o odor e consistência das fezes, pelagem, saúde e bem-estar do animal.

Os alimentos industrializados beneficiam os animais proporcionando uma alimentação nutricionalmente completa e equilibrada. Cães e gatos tem exigências nutricionais muito diferentes dos humanos e, por isso, é um grande erro dar sobras de comidas a esses animais. Um regime alimentar pobre pode resultar em uma série de problemas de saúde, como obesidade, complicações renais e digestivas (ALIMENTOS, 2009).

Segundo Alves (2003), vários procedimentos e práticas adotadas na área de alimentação humana como as Boas Práticas de Fabricação (BPF) e a Análise de Perigos e Pontos Críticos de Controle (APPCC) são altamente recomendáveis para a produção de alimentos para cães e gatos, visto que oferecem mecanismos de redução de perigos e ações preventivas, visando garantir a segurança do alimento oferecido aos animais.

O estudo de caso foi realizado na Nutriara Alimentos Ltda. e tem como objetivo analisar o impacto da implementação das BPF na indústria de alimentos para animais.

A Nutriara Alimentos Ltda. foi fundada em 1991, na cidade de Arapongas, Paraná e ocupa o 8 o lugar mundial no segmento, com um faturamento anual de aproximadamente US\$ 270 milhões (TAYLOR, 2009). Com o objetivo de ser competitiva no mercado, manter a liderança conquistada e expandir o comércio internacional, desde o ano de 2005, a empresa trabalha na implementação do Programa Educacional Nutriara Segurança do Alimento (PENSA), sendo a implementação das BPF, a primeira ação do programa.

A produção de alimentos industrializados para cães e gatos apresentou, nas últimas décadas, um significativo crescimento. Este mercado faturou, em nível mundial, no ano de 2007, US\$ 45 bilhões, que comparado com o ano de 2002, representa um crescimento de $43 \%$ (TAYLOR, 2009).

A produção brasileira em 2008 foi de aproximadamente 1,8 milhão de toneladas e o faturamento de US\$ 3,07 bilhões. A população nacional estimada de cães é de 31 milhões e de gatos 15 milhões. Estes números levam o Brasil, no mercado mundial, ao segundo lugar em volume de produção de alimentos para animais e em população de cães e gatos, além do sétimo lugar mundial em faturamento. Hoje, os alimentos industrializados representam apenas $45 \%$ da demanda total de alimentos, sendo, portanto um mercado com grande potencial de crescimento (SETOR, 2008;2009). 
A Associação Nacional dos Fabricantes de Alimentos para Animais de Companhia (ANFALPET), afirma que o mercado pet brasileiro movimenta anualmente cerca de R\$ 9 bilhões (LOTURCO, 2009; SETOR, 2009).

O segmento de alimentos industrializados para animais está subordinado ao Ministério da Agricultura Pecuária e Abastecimento (MAPA) do Brasil, que, formula e executa as políticas para garantir a segurança dos alimentos. As indústrias de alimentos devem atender as especificações e implementar as BPF (BRASIL, 2007). Para isto, investem em adequações das instalações, formação de equipes, mudanças comportamentais dos colaboradores, através de implementação de procedimentos e treinamentos.

As BPF são um conjunto de normas que definem a infraestrutura e os procedimentos higiênicos, sanitários e operacionais aplicados em todo o fluxo de produção, desde a obtenção das matérias-primas até a distribuição do produto final, com o objetivo de garantir a qualidade, a conformidade e a segurança dos produtos destinados à alimentação animal (BRASIL, 2007).

As BPF correspondem à sigla em inglês GMP, mundialmente conhecida como Good Manufacturing Practices. Segundo Canto (2009), o marco histórico da origem das GMP está em 1964, num episódio ocorrido nos Estados Unidos da América (EUA). O governo americano preocupado com a situação dos produtos de higiene pessoal e dos cosméticos em geral, solicitou ao seu Departamento de Saúde, Educação e do Bem-Estar, que abriga o Food and Drug Administration (FDA), que realizasse uma análise desses produtos no mercado. Nesse estudo que envolveu 127 fabricantes, totalizando 1.960 amostras, apurou-se que $19,5 \%$ das amostras analisadas apresentaram contaminação microbiológica. O governo americano determinou que fossem adotadas rápidas ações normativas e introduzissem uma ferramenta ou dispositivo que, por força de lei, corrigisse de vez aquela situação crítica de saúde pública. O FDA saiu a campo e colocou em prática a regulamentação das GMP a partir de 1969.

De acordo com Canto (2009), as GMP tem três objetivos básicos. O primeiro é a unificação da linguagem dos princípios básicos de como ter e obter boas práticas de fabricação para produtos destinados à saúde humana e animal. O resultado final será a qualidade de produtos acabados dentro dos padrões (especificações) e, consequentemente, a perpetuação da imagem e da vida da organização na comunidade. O segundo objetivo está em comprovar que a empresa que possui GMP já se encontra em estágio superior na qualidade de seus produtos. O terceiro objetivo é atingir a qualidade assegurada dos produtos acabados.

\subsection{Justificativa}

A escolha deste tema deve-se ao escasso número de publicações nacionais na área de gestão de qualidade na indústria de alimentos para animais e à possibilidade de apresentar um estudo de caso sobre uma empresa de grande porte. 
Outro fator que motivou a escolha do tema é a importância da implementação das BPF, que são consideradas pré-requisitos para a implementação do sistema APPCC (ALIMENTOS, 2008), através da constatação de atendimento de requisitos e a análise de parâmetros significativos para a imagem da empresa no mercado, como o percentual de reclamações referentes à qualidade dos produtos no Serviço de Atendimento ao Cliente (SAC) e o percentual de Produtos Acabados (PA) não conformes devolvidos à fábrica. A implementação das BPF em indústria de alimentos para animais é uma metodologia importante para estabelecer e padronizar procedimentos e instruções de trabalho, conscientizar colaboradores para práticas adequadas de higiene e manipulação dos alimentos, reduzir a níveis aceitáveis as contaminações e garantir a segurança e qualidade dos produtos.

\subsection{Objetivo Geral}

O objetivo geral deste estudo foi analisar o impacto da implementação das BPF em uma indústria de alimentos para animais.

\subsection{Objetivos Específicos}

a) Verificar o percentual de atendimento do "Roteiro de Inspeção das BPF em Estabelecimentos Fabricantes de Produtos Destinados à Alimentação Animal" antes e após a implementação das BPF;

b) Analisar o impacto da implementação das BPF no percentual de devolução de produtos não conformes, antes e após a implementação das BPF;

c) Analisar o percentual de reclamações referentes à qualidade dos produtos no Serviço de Atendimento ao Cliente (SAC), antes e após a implementação das BPF.

\section{REFERENCIAL TEÓRICO E LEGAL}

O MAPA, através da Normativa $N^{\circ} 15$ de 2003 estabelece os procedimentos básicos de fabricação para os estabelecimentos que processam resíduos de animais para a fabricação de farinhas e gorduras destinadas à alimentação animal (BRASIL, 2003b).

Além disso, a Instrução Normativa $N^{\circ} 17$, de 07 de abril de 2008, proíbe em todo território nacional, a fabricação, na mesma planta, de produtos destinados à alimentação de ruminantes e de não ruminantes, exceto os estabelecimentos que atendem aos seguintes requisitos: possua linhas separadas para produção de produtos para ruminantes e não ruminantes; esteja com as BPF implementadas, possua e aplique procedimentos validados para o controle da contaminação cruzada entre os produtos destinados à alimentação de ruminantes e os produtos que contenham ingredientes de origem animal em sua formulação, desde o recebimento até a sua expedição e transporte; ter 
um programa de monitoramento por meio de análise de laboratório e tenha as medidas corretivas descritas no caso de ocorrência de contaminação por ingrediente de origem animal (BRASIL, 2008).

A qualidade das matérias-primas, a arquitetura dos equipamentos e das instalações, as condições higiênicas do ambiente de trabalho, a saúde dos colaboradores são fatores importantes a serem considerados na produção de alimentos seguros e de qualidade, devendo, portanto ser considerados nas BPF (TOMICH et al., 2009). Há evidências de investimentos no aperfeiçoamento de técnicas que promovam à qualidade higiênicosanitária, no qual destaca-se o treinamento de colaboradores. Dentro deste contexto, algumas dificuldades encontradas foram: o nível de escolaridade dos colaboradores manipuladores de alimentos, sua indisponibilidade de horário para realização de treinamentos e a ausência de participação da gerência (BELLIZZI et al., 2005).

Segundo Ramos, Cunha e Schmidt (2005), é necessária a conscientização dos colaboradores para que pratiquem as boas práticas de higiene, garantindo produtos saudáveis, confiáveis e de qualidade reconhecida. As empresas que não derem importância a estes requisitos mínimos de fabricação de alimentos, provavelmente não conseguirão sobreviver no mercado cada vez mais competitivo.

Entre as principais dificuldades relacionadas à implementação das BPF em indústrias pode-se destacar a falta de pessoal capacitado para este objetivo, outro obstáculo é a ausência de investimentos. Como se trata, sobretudo, de um programa que exige mudanças comportamentais e disciplinares, reside aqui um fator muito importante para seu êxito (MICHALCZYSZYN et al, 2008).

No Brasil, a Resolução Mercado Comum do Sul (MERCOSUL) № 80 de 11 de outubro de 1996 é a precursora do MAPA que aprova o Regulamento Técnico sobre as condições higiênico-sanitárias e de BPF para estabelecimentos elaboradores/industrializadores de alimentos (BRASIL, 1997; BRASIL, 2010).

A Portaria № 368, de 04 de setembro de 1997 do MAPA, aprova o Regulamento Técnico sobre as condições higiênico-sanitárias e de BPF para os estabelecimentos elaboradores/ industrializadores de alimentos. Este regulamento aplica-se a todo estabelecimento no qual se realizam algumas das seguintes atividades: elaboração/ industrialização, fracionamento, armazenamento e transporte de alimentos destinados ao comércio nacional ou internacional. Esta Portaria define BPF como os procedimentos necessários para a obtenção de alimentos inócuos e saudáveis (BRASIL, 1997).

A Circular № 175, de 16 de maio de 2005 do MAPA estabelece os procedimentos de verificação dos Programas de Autocontrole. O Departamento de Inspeção de Produtos de Origem Animal (DIPOA) optou por um modelo de inspeção sanitária baseado no controle do processo. Este procedimento fundamenta-se na inspeção contínua e sistemática de todos os fatores que, de alguma forma, podem interferir na qualidade higiênico-sanitária dos produtos. Todo o processo de produção é visualizado como um macroprocesso, que, do ponto de vista da inocuidade do produto, é composto de vários 
processos, agrupados basicamente em quatro grandes categorias: matérias-primas, instalações e equipamentos, pessoal e metodologia de produção que estão envolvidos na qualidade higiênico-sanitária do produto final (BRASIL, 2005).

Especificamente no que refere à indústria de alimentos para animais, o MAPA, estabeleceu e aprovou através da Instrução Normativa № 1, de 13 de fevereiro de 2003, o Regulamento Técnico sobre as condições higiênico-sanitárias e de BPF para os estabelecimentos fabricantes de produtos destinados à alimentação animal (BRASIL, 2003a). Esta Instrução Normativa foi revogada pela Instrução Normativa № 4, de 23 de fevereiro de 2007 (BRASIL, 2007).

Como principais referências para este trabalho foram utilizadas:

a) Instrução Normativa № 1 (BRASIL, 2003a) para os dados obtidos até 23 de fevereiro de 2007;

b) Instrução Normativa № 4 (BRASIL, 2007) para os dados obtidos após 23 de fevereiro de 2007.

A IN n⒋2007, estabelece a entrega do Plano de implementação das BPF, incluindo o manual e também que os estabelecimentos fabricantes e fracionadores de alimentos para animais atendam às especificações contidas no Regulamento e Roteiro de Inspeção (BRASIL, 2007).

Os procedimentos devem ser revisados pelo menos uma vez ao ano e sempre que houver qualquer modificação nos procedimentos operacionais, visando avaliar a sua eficiência e ajustando-os, quando necessário.

Todas as etapas descritas nos procedimentos devem ser registradas e a verificação documentada, para comprovar a sua execução. Os registros devem ser datados e assinados pelo responsável pela execução de cada etapa do procedimento.

Todas as operações devem ser realizadas de acordo com o manual de procedimentos de BPF, que deve ser claro e preciso o bastante para que todas as operações sejam executadas conforme o descrito e que o objetivo esperado seja atingido.

São necessárias as descrições dos procedimentos envolvidos no processo produtivo dos alimentos e as gerências e supervisões devem estar engajadas para elaborar, revisar, aprovar e implementar os procedimentos das BPF. É imprescindível que a direção da empresa esteja comprometida para disponibilizar recursos materiais e humanos a fim de adequar as não conformidades detectadas nas instalações e ações de motivação dos colaboradores (NASCIMENTO; BARBOSA, 2007).

As BPF são ferramentas da filosofia do sistema de garantia da qualidade, que consiste em estabelecer normas que padronizem e definam procedimentos e métodos que regulamentam todas as atividades de fabricação de um produto. $O$ conceito é abrangente, 
pois envolve a participação das pessoas, o processo de produção, a condição de uso dos equipamentos, as matérias-primas, as embalagens, os rótulos, a manutenção, a segurança e a proteção ambiental, o armazenamento dos insumos e produtos, a expedição, a distribuição e o transporte, dentro do objetivo de assegurar a qualidade do produto final. As auditorias de conformidade dos programas de Qualidade (BPF/ Procedimento Padrão de Higiene Operacional) são fundamentais para que a empresa obtenha a validação desta implementação (CANTO, 2009; WINCKLER, 2007).

\section{PROCEDIMENTOS METODOLÓGICOS}

O estudo de caso foi realizado através de levantamento e análise de dados registrados na Nutriara Alimentos Ltda. Unidade Arapongas - Paraná com dados compreendidos no período de junho de 2005 a dezembro de 2008. Este período abrange as fases anterior e posterior à implementação das BPF, através dos seguintes estudos:

a) Comparativo e avaliação do percentual de atendimento dos Roteiros de Inspeção da IN no 1/2003 (BRASIL, 2003a) e da IN no 4/2007 (BRASIL, 2007):

- O Roteiro de Inspeção da IN no1/2003 do Ministério da Agricultura, Pecuária e Abastecimento avalia 129 itens. O estabelecimento é classificado conforme o atendimento ao Roteiro de Inspeção:

Grupo 1: 100 a 70\% de atendimento dos itens imprescindíveis

Grupo 2: 69 a 30\% de atendimento dos itens imprescindíveis

Grupo 3: 29 a 0\% de atendimento dos itens imprescindíveis

- O Roteiro de Inspeção da IN no 4/2007 avalia 157 itens. Os itens são classificados em Necessários e Imprescindíveis.

A classificação do estabelecimento será obtida pela pontuação no atendimento ao Roteiro de Inspeção:

Pontuação $=\{($ Soma dos itens imprescindíveis atendidos sobre 0 total de itens imprescindíveis do roteiro $\times 100) \times 2+$ (Soma dos itens necessários atendidos sobre 0 total de itens necessários do roteiro $X 100)\} / 3$.

Os itens que não se aplicam (N.A.) serão desconsiderados na soma dos itens atendidos.

De acordo com o MAPA, a classificação do estabelecimento em algum dos grupos abaixo acarretará em diferentes medidas ou concessões, conforme quadro a seguir. 


\begin{tabular}{|c|c|l|}
\hline Pontuação & Grupo & Classificação do estabelecimento \\
\hline 81 a 100 pontos & 1 & Estabelecimentos fabricantes de produtos com medicamentos \\
61 a 80 pontos & 2 & Estabelecimentos terão prazos para se adequarem. \\
\hline 41 a 60 pontos & 3 & Estabelecimentos terão prazos para se adequarem. \\
0 a 40 pontos & 4 & Estabelecimentos sofrerão interdição temporária até adequação. \\
\hline
\end{tabular}

Quadro 1 - Classificação dos estabelecimentos de acordo com a pontuação MAPA

Fonte: (BRASIL, 2003; BRASIL, 2007).

Os prazos propostos no cronograma de adequações apresentado pelos estabelecimentos serão avaliados pelo MAPA e poderão ser aceitos ou redefinidos (BRASIL, 2007).

Os Roteiros de Inspeção da IN no 1/2003 foram aplicados em 2005 (Junho e Dezembro/2005) e em 2006 (Dezembro/2006). Em 2007 (Dezembro/2007) e 2008 (Dezembro/2008) aplicou-se o Roteiro de Inspeção da IN no 4/2007 (BRASIL, 2007).

Primeiramente apresentaram-se os dados obtidos através da avaliação do Roteiro de Inspeção, desconsiderando a irregularidade de tempo. Posteriormente realizou-se uma análise de estatística básica, com períodos regulares de tempo e Instruções Normativas distintas, desta forma os tratamentos foram: Dez/2005; Dez/2006 sobre a IN no 1/2003 (BRASIL, 2003 a) e Dez/2007; Dez/2008 sobre a IN no 4/2007 (BRASIL, 2007); no intuito de mostrar o crescimento obtido com a implementação das BPF, através de desvio padrão e análise de regressão (UFV, 2010).

\section{b) Avaliação do percentual de devolução de produtos não conformes em relação à quantidade expedida:}

A empresa possui um procedimento para a devolução de produtos não conformes. Este procedimento contempla as seguintes etapas; a área comercial preenche um registro informando o nome do produto, a data de fabricação ou validade, a quantidade e a causa da devolução; o gerente comercial avalia o registro e se considerar procedente, encaminha à diretoria técnica; esta aprova a devolução do produto não conforme para a unidade fabril; cópia deste registro aprovado é encaminhada ao departamento de Qualidade; o supervisor de Qualidade recebe o produto devolvido conforme o registro previamente recebido analisa a causa da devolução, elabora um laudo de devolução e informa a disposição para o departamento de Produção; os laudos de devolução são arquivados e apresentados em reunião semanal ao Comitê de Qualidade.

O percentual de produtos devolvidos será calculado somando o total em toneladas de produtos devolvidos a fábrica durante o ano, dividido pelo total em toneladas de produtos expedidos durante o ano, multiplicado por 100. 
No estudo de caso serão avaliadas as quantidades totais de produtos devolvidos à fábrica em relação às quantidades expedidas nos anos de 2005, 2006, 2007 e 2008. Primeiramente, apresentaram-se os dados obtidos no período de janeiro a junho de 2005; julho a dezembro de 2005, janeiro a dezembro de 2006, 2007 e 2008. Posteriormente, realizou-se uma análise de estatística básica, com períodos regulares de tempo, desta forma os tratamentos foram os anos de 2005, 2006, 2007 e 2008, no intuito de mostrar a queda obtida nos percentuais de devoluções com a implementação das BPF, através de desvio padrão e análise de regressão (UFV, 2010).

c) Avaliação do percentual de reclamações referentes à qualidade dos produtos no Serviço de Atendimento ao Cliente:

O Serviço de Atendimento ao Cliente (SAC) é terceirizado. Uma empresa contratada realiza este atendimento para a Nutriara Alimentos Ltda. e dispõe de uma médica veterinária e atendentes. Esta equipe é treinada pelos Departamentos Técnicos e Qualidade da Nutriara.

Toda ligação telefônica gera uma ocorrência, que é considerada procedente e é classificada em elogio, pedido, sugestão, reclamação, informação clínica, informação de produto, informação, informação de promoção. Trataremos neste estudo, somente as reclamações de produtos devido à qualidade.

No estudo de caso foram comparadas as quantidades de reclamações no SAC relacionadas aos Produtos - Qualidade nos anos de 2005, 2006, 2007 e 2008.

A quantidade de reclamações no SAC relacionada à qualidade dos produtos foi considerada como o marco inicial (100\%) referente ao ano de 2005. Este ano a empresa iniciou a implementação das BPF. Os demais anos foram comparados em relação ao ano de 2005. Posteriormente realizou-se uma análise de estatística básica, no intuito de mostrar a queda obtida nos percentuais de reclamações com a implementação das BPF, através de desvio padrão e análise de regressão (UFV, 2010).

\section{RESULTADOS E DISCUSSÃO}

Os percentuais de atendimento dos Roteiros de Inspeção da IN no 1/2003 (BRASIL, 2003 a) e da IN no 4/2007 (BRASIL, 2007), juntamente com a respectiva data de realização e classificação do estabelecimento obtida, estão apresentados na Figura 1. 


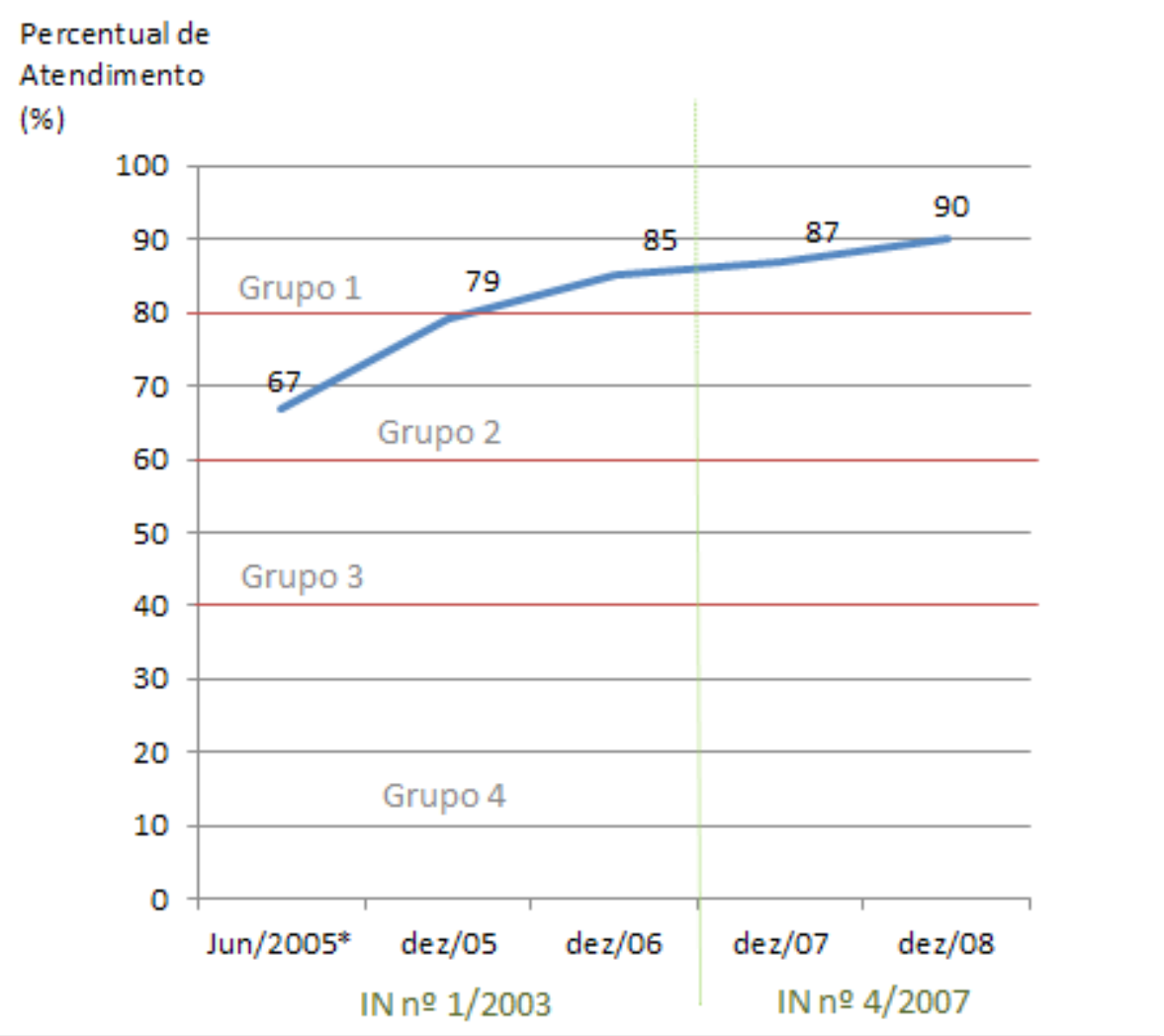

Figura 1 - Percentual de Atendimento dos Roteiros de Inspeção e suas respectivas Instruções Normativas

Fonte: Do autor (2010).

* Antes da implementação das BPF.

Referente à Figura 1, pode-se observar os percentuais obtidos após avaliação dos Roteiros de Inspeção das respectivas Instruções Normativas. Observa-se que em junho de 2005, período anterior à implementação das BPF, o percentual de atendimento do Roteiro de Inspeção da IN № 1/2003 obtido foi de 67\% com classificação do estabelecimento em Grupo 2. A empresa, não apresentava programa de BPF, antes desta data, desta forma a primeira avaliação do Roteiro de Inspeção as BPF avalia as condições em que se encontrava a empresa.

Após esta primeira avaliação obtendo tal classificação a empresa necessitou apresentar ao MAPA um plano de ação para correção e adequação das não-conformidades dos requisitos avaliados (BRASIL, 2003 a), no qual é procedimento padrão, a cada avaliação de Roteiro de Inspeção realizada, para implementação e manutenção das BPF.

Neste período inicial, a empresa identificou que os principais requisitos não atendidos no Roteiro de Inspeção foram referentes às instalações e edificações, assim como de pessoal (treinamentos) e documentação. Mediante esta constatação, realizou-se a contratação de uma empresa consultora, que formou uma equipe gestora multidisciplinar para implementar as BPF na empresa. 
Esta equipe identificou colaboradores que foram treinados com o objetivo de tornarem-se facilitadores da implementação das BPF. Estes colaboradores receberam 40 horas de treinamentos na IN № $1 / 2003$, no qual elaboraram uma cartilha com conteúdo de linguagem de fácil entendimento, contendo figuras para treinar os demais colaboradores, redigiram os procedimentos operacionais e instruções de trabalho, revisaram conjuntamente as rotinas operacionais, validaram e aprovaram as informações contidas nestes documentos. Também elaboraram material didático para treinamento de motoristas e visitantes, assim como o manual das BPF. Em conjunto a equipe multidisciplinar e a gerência industrial trabalharam no plano de adequações das instalações e edificações.

Após a realização deste primeiro plano de ação, em dezembro de 2005 , realizou-se novamente a avaliação do atendimento do Roteiro de Inspeção da IN no 1/2003, obtendose valor de $79 \%$ e a classificação do estabelecimento em Grupo 1. Pode-se observar que com a realização e aplicação do primeiro plano de ação, houve um salto significativo no atendimento aos requerimentos da Instrução Normativa no 1/2003 (BRASIL, 2003 a), no qual este representa um valor de crescimento de 12 pontos percentuais.

A avaliação do atendimento ao Roteiro de IN $n$ ㅇ 1/2003, foi realizada anualmente, para tal observa-se que no ano posterior, dezembro de 2006, a empresa apresentou-se com valor de $85 \%$ ao atendimento dos requisitos, mantendo a classificação de grupo.

Com a realização dos planos de ação, a implementação dos procedimentos operacionais e a qualificação dos colaboradores através de treinamentos contínuos nas BPF, relacionados à higiene e a manipulação dos alimentos, foram consolidados os conhecimentos contribuindo para o atendimento do Roteiro de Inspeção. Nascimento e Barbosa (2007) afirmam que é imprescindível que a direção da empresa esteja comprometida para disponibilizar recursos materiais e humanos a fim de adequar as não conformidades detectadas nas instalações e ações de motivação dos colaboradores.

No ano de 2007, a IN no 1/2003 foi revogada e entrou em vigor a IN no 4/2007. Esta Instrução Normativa vigente ficou mais detalhada e foram acrescentados 28 itens. A pontuação para a classificação do estabelecimento considera a média ponderada dos itens imprescindíveis e itens necessários.

Realizando-se nova avaliação ao atendimento do Roteiro de Inspeção, referente à IN no 4/2007, em dezembro de 2007 , foi obtido valor de $87 \%$, com classificação do estabelecimento em Grupo 1. A empresa elaborou um plano de ação para adequação das não-conformidades evidenciadas na auditoria.

Os planos de ação realizados são medidas que devem ser providenciadas para que atenda aos requisitos da Instrução Normativa, basicamente foram adequações de documentos, melhorias nas instalações e treinamentos de colaboradores.

Ao avaliar-se o Roteiro de Inspeção, referente à IN no 4/2007, em dezembro de 2008, obteve-se valor de 90\%, mantendo a classificação do estabelecimento em Grupo 1. 
Seguindo uma análise nos valores apresentados na Figura 1, de uma forma geral desde a primeira avaliação, pode-se observar que houve considerável crescimento ao atendimento as respectivas Instruções Normativas. Este crescimento evidenciado ao longo do período analisado foi de 23 pontos percentuais. Porém o período analisado não é regular se consideramos a primeira avaliação como sendo junho de 2005 e distribuído em duas Instruções Normativas diferentes. Para tal, na Tabela 1, apresentou-se uma análise de estatística básica, com períodos regulares de tempo e Instruções Normativas distintas, no intuito de mostrar o crescimento obtido no período em questão.

Tabela 1 - Análise estatística dos Percentuais de Atendimento dos Roteiros de Inspeção

\begin{tabular}{l|c|c|c|c|c|c|}
\hline $\begin{array}{c}\text { Data } \\
\text { \% de }\end{array}$ & Dez/2005 & Dez/2006 & Dez/2007 & Dez/2008 & DP* & DP* \\
atendimento & 89 & 85 & 90 & $4,65 * *$ & $2,51 * * *$ \\
* Desvio Padrão & & & & \\
** Valor de desvio padrão obtido entre o período de Dez. 2005 a Dez. 2008. \\
*** Valor de desvio padrão obtido considerando o período Dez. 2006 a Dez. 2008.
\end{tabular}

Fonte: Do autor (2010)

Ao avaliar-se o período de implementação das BPF, em períodos regulares de tempo, observa-se que o desvio padrão dos percentuais é relativamente baixo quando considerado o período de dezembro de 2005 a dezembro de 2008, no qual o valor obtido é de 4,65 pontos. E para o período de dezembro de 2006 a dezembro de 2008, o valor obtido através do desvio padrão é de 2,51 pontos. À medida que são realizadas novas avaliações do Roteiro de Inspeção e os planos de ações vão sendo realizados, obtêmse aumento no valor percentual com diminuição no desvio padrão. Este crescimento relatado no presente trabalho pode ser observado na equação $y=3,5 x-287,5$, que demonstra a evolução linear quando considerado o período em questão, obtendo-se um valor de R2 elevado de 0,9459. Como se trata de um reduzido período de avaliação, pode-se apenas fazer inferências quanto ao período avaliado. Porém é possível observar através da regressão aplicada que nos próximos anos, a empresa em questão obterá valores próximos ao atendimento de $100 \%$ dos requisitos.

Uma consideração a ser observada, é de que a leitura do Roteiro de Inspeção às Instruções Normativas e os respectivos percentuais vão aumentando, e refletem diretamente na qualidade do produto, podendo ser observado nos valores de percentuais de devolução de produtos não-conformes em relação à quantidade expedida são apresentados na Tabela 2. 
Tabela 2 - Percentuais de devolução de produtos não-conformes em relação à quantidade expedida.

\begin{tabular}{|l|c|}
\hline Período & Devolução /quantidade expedida (\%) \\
\hline Jan a Jun/2005* & 0,66 \\
\hline Jul a Dez/2005 & 0,15 \\
\hline Jan a Dez/2006 & 0,05 \\
\hline Jan a Dez /2007 & 0,05 \\
\hline Jan a Dez /2008 & 0,03 \\
\hline & $*$ Antes da implementação das BPF. \\
\hline
\end{tabular}

Ao observar-se a Tabela 2, constata-se que no período anterior a implementação das BPF, compreendido em janeiro a junho de 2005, o valor obtido foi de $0,66 \%$, refere-se aos produtos acabados e expedidos que eram devolvidos à empresa. As principais causas das devoluções observadas neste período tratam-se de produtos fora dos padrões de especificações. No período inicial à implementação das BPF foram definidos os padrões de especificações das matérias-primas, produtos acabados e embalagens, sendo especificados os limites de aceitação e rejeição, da mesma forma foram elaborados os procedimentos operacionais e as instruções de trabalhos, com posterior treinamento dos colaboradores e com monitoramento pela supervisão. Em auxílio à prevenção de contaminação biológica, tanto em matéria prima armazenada, quanto em produtos acabados, realizou-se a contratação de uma empresa terceira para auxiliar no controle integrado de pragas.

Observa-se, após a implementação destas ações, que o percentual de devolução de produtos acabados não-conformes reduziu para 0,15\% no período compreendido de julho a dezembro de 2005 . Este percentual corresponde à redução de $75 \%$ da quantidade devolvida anterior a implementação das BPF. Os principais procedimentos operacionais que impactaram este requisito foram o estabelecimento de cronograma de higienização das instalações e equipamentos, o treinamento dos colaboradores e a implementação do controle integrado de pragas, assim como a rejeição de matérias-primas contendo contaminantes biológicos.

Destaca-se ainda que após um ano, no período compreendido de janeiro a dezembro de 2006, este percentual novamente reduz em $66 \%$, atingindo o valor de $0,05 \%$. 0 valor de $0,05 \%$ mantém-se no período de janeiro a dezembro de 2007 . Para o período compreendido de janeiro a dezembro de 2008 , obtém-se valor de $0,03 \%$.

Da mesma forma, como foi relatado para os percentuais de atendimento dos Roteiros de Inspeção da IN no 1/2003 e da IN no 4/2007, as faixas de período em questão dos valores percentuais de devolução de produtos não-conformes em relação à quantidade expedida, não são uniformes. Buscando-se uniformizar os dados analisados, realizouse uma análise de estatística básica, com períodos regulares de tempo e Instruções 
Normativas distintas, no intuito de mostrar o comportamento do percentual obtido no período em questão, sendo apresentado na Tabela 3.

Tabela 3 - Análise estatística do percentual de devolução de produtos não conformes em relação à quantidade expedida.

\begin{tabular}{c|c|c|c|c|c|c} 
Período & $\begin{array}{c}\text { Jan a } \\
\text { Dez/2005 }\end{array}$ & $\begin{array}{c}\text { Jan a } \\
\text { Dez/2006 }\end{array}$ & $\begin{array}{c}\text { Jan a } \\
\text { Dez/2007 }\end{array}$ & $\begin{array}{c}\text { Jan a } \\
\text { Dez/2008 }\end{array}$ & DP* & DP* \\
$\begin{array}{c}\text { \% Devolvida/ } \\
\text { Quantidade } \\
\text { Expedida }\end{array}$ & $0,41 \%$ & $0,05 \%$ & $0,05 \%$ & $0,03 \%$ & $0,183 * *$ & $0,011 * * *$ \\
\hline
\end{tabular}

* Desvio Padrão

** Valor de desvio padrão obtido entre o período de Jan/Dez de 2005 a Jan/Dez de 2008

*** Valor de desvio padrão obtido considerando o período Jan/Dez de 2006 a Jan/Dez de 2008

Fonte: Do autor (2010)

Analisando a Tabela 3, obtém-se um valor médio de percentual de devolução de produtos não-conformes em relação à quantidade expedida de $0,41 \%$ quando considerado um período único entre janeiro a dezembro de 2005. Desta forma, quanto avaliados períodos regulares de tempo, observa-se que o desvio padrão dos percentuais é relativamente baixo quando considerado o período de 2005 a 2008, no qual o valor obtido é de 0,183 pontos. E para o período de 2006 a 2008, o valor obtido através do desvio padrão é de 0,011 pontos.

Na medida em que são implementadas as BPF e os planos de ação são concluídos, observaram-se as melhoras na qualidade do produto acabado, devido a redução no percentual de devolução em relação à quantidade expedida e com diminuição no desvio padrão.

Considerando o período avaliado, a melhor equação para demonstrar a evolução é uma equação linear platô, com dois pontos para equação e três pontos para o platô, no qual é dada a equação por $y=722,21 x-0,36$, obtendo-se um valor de $R 2$ elevado de 0,9286.

Quanto aos percentuais de reclamações referentes à qualidade dos produtos no SAC, os valores estão apresentados na Tabela 4. 
Tabela 4 - Percentual de reclamações referentes à qualidade dos produtos registrado no SAC

\begin{tabular}{|c|c|c|c|c|c|c|}
\hline Ano & 2005 & 2006 & 2007 & 2008 & DP* & DP* \\
\hline \% Reclamações & 100 & 60 & 51 & 49 & $23,82 * *$ & $5,86 * * *$ \\
\hline \multicolumn{7}{|l|}{ * Desvio Padrão } \\
\hline
\end{tabular}

Fonte: Do autor (2010)

O ano de 2005 refere-se ao ano que a empresa inicia a implementação das BPF e a quantidade de reclamações no SAC devido à qualidade dos produtos foi convencionada como sendo valor máximo de $100 \%$. A adequação dos procedimentos operacionais, incluindo nesta ação a qualificação dos fornecedores, a higienização das instalações, equipamentos e utensílios, a elaboração de padrões de especificações de matériasprimas e produtos acabados, os treinamentos de colaboradores e a prevenção da contaminação cruzada. Dentro deste contexto, no ano posterior o percentual de reclamações no SAC devido à qualidade dos produtos reduz para $60 \%$ em comparação ao ano de 2005, no qual observa-se uma redução em $40 \%$. Os percentuais obtidos nos anos de 2007 e 2008 com a implementação dos procedimentos operacionais foram de 51 e 49\%, respectivamente. (BRASIL, 2007)

Fica evidenciado que na medida em que a implantação da BPF se consolida, e os planos de ação vão sendo realizados, pode-se observar que houve redução significativa no percentual de reclamação quanto à qualidade do produto acabado. Desta forma, realizou-se uma análise de estatística básica, com períodos regulares de tempo e Instruções Normativas distintas, no intuito de mostrar o comportamento do percentual obtido no período em questão.

Analisando a Tabela 5, obtém-se um valor de desvio padrão dos percentuais, relativamente alto quando considerado o período de 2005 a 2008, no qual o valor obtido é de 23,82 pontos. Porém analisando o período de 2006 a 2008, o valor obtido através do desvio padrão reduz, obtendo-se valor de 5,86 pontos, mostrando-se a maior uniformidade entre os períodos no qual as BPF estão implementadas, podendo observar a redução gradativa no percentual de reclamações.

Pode-se observar um decréscimo acentuado, após a implementação das BPF, no qual considerando o período avaliado, a melhor equação para demonstrar a evolução é uma equação linear platô, com dois pontos para equação e três pontos para o platô, no qual é dada a equação por y = 140,00x - 40, obtendo-se um valor de R2 elevado de 0,9831. Pode-se fazer uma inferência quanto à evolução do gráfico, no qual espera-se que o mesmo atinja um platô buscando a estabilidade.

Analisando os dados obtidos na implementação das BPF apresentados no presente estudo, pode-se observar que traz a empresa benefícios quanto à redução no percentual 
de devolução dos produtos, redução do percentual de reclamações dos produtos no SAC, ambos os benefícios são observáveis proporcionalmente na medida em que os percentuais de atendimento ao Roteiro de Inspeção são aumentados.

Os resultados positivos observados nos parâmetros analisados estão de acordo com Canto (2009) que afirma que a implementação das BPF tem objetivos básicos como a unificação dos procedimentos que resulta em produtos acabados dentro das especificações e demonstra que a empresa encontra-se em estágio superior na qualidade.

Alves (2003) em pesquisa realizada em empresas brasileiras fabricantes de alimentos para cães e gatos identificou que as oportunidades de melhorias para a implementação das BPF eram as questões relacionadas aos hábitos higiênicos e ao programa de treinamento de pessoal. No presente estudo de caso, verificou-se que o investimento em treinamentos dos colaboradores, a elaboração de cartilha com linguagem de fácil entendimento e contendo figuras e o comprometimento dos gestores foram fundamentais para o sucesso da implementação das BPF.

No ano de 2009 a empresa continuou melhorando os parâmetros de qualidade e implementou o sistema APPCC, ocorreram investimentos nas instalações e equipamentos, treinamentos para os colaboradores sobre conceitos de segurança do alimento. Em 2008 e 2009 ocorreram auditorias externas que recomendaram a empresa à certificação no Programa Integrado de Qualidade Pet (PIQPET) da ANFALPET.

Segundo França (2010) o PIQPET é um programa que integra representantes da comunidade científica, do setor público e da indústria e tem como objetivo contribuir para a evolução da qualidade dos alimentos para animais de estimação oferecidos no mercado, através da adequação da cadeia de produção visando aumento da qualidade, reconhecimento do consumidor e cumprimento de todas as normas e legislações vigentes.

\section{CONCLUSÃO}

O estudo de caso realizado na empresa industrializadora de alimentos para animais demonstra que a implementação das BPF, segundo as Instruções Normativas do MAPA, apresentou resultados significativos.

A empresa implementou as BPF através da elaboração, da verificação e do monitoramento dos procedimentos operacionais. Os principais procedimentos que impactaram os resultados foram a higienização das instalações e equipamentos, o controle integrado de pragas, o estabelecimento de padrões de especificações de matérias-primas e produtos acabados e os treinamentos dos colaboradores.

O atendimento aos Roteiros de Inspeção das Instruções Normativas do MAPA foram crescentes com a implementação das BPF na empresa e através das conclusões dos planos de ação, os resultados satisfatórios foram obtidos. À medida que os percentuais 
de atendimento ao Roteiro de Inspeção aumentaram ocorreu redução no percentual de devolução dos produtos e redução do percentual de reclamações dos produtos no SAC.

Pode-se concluir que a implementação das BPF impactou positivamente na empresa, fato comprovado pela redução no percentual de reclamações no SAC devido à qualidade dos produtos e redução da devolução dos produtos não conformes.

A implementação das BPF também pode ser considerada um argumento de marketing na comercialização do produto acabado, garantindo a segurança dos alimentos de animais que tem convívio próximo e valor afetivo inestimável seus proprietários. 


\title{
ANALYSIS OF THE GOOD MANUFACTURING IMPLEMENTATION IN AN ANIMAL FOOD INDUSTRY
}

\begin{abstract}
The case study was realized in Nutriara Foods Ltda, Parana and had as aim to analyze the Good Manufacturing Practices implementation impact in an animal food industry. The period of the die analysis was from 2005 to 2008, in which was rated the percentage of compliance to the Normative Instructions of the Inspection Schedules numbers 1 and 4 from Agriculture, Cattle and Supply Ministry of Brazil; the percentage of products devolution and the percentage of complaints in the Customer Service referring to the products quality, before and after the GMP implementation. The compliance to the Inspection Schedules increased with the implementation of the GMP in the company. Due to the GMP implementation, both the product devolution percentage and the customer complaints decreased. In conclusion, the GMP implementation had a positive impact in the company.
\end{abstract}

Key words: Good Manufacturing Practices. Feed.

\section{REFERÊNCIAS}

ALIMENTOS. Análise de Perigos e Pontos Críticos de Controle - APPCC. Disponível em: <http://www.anvisa.gov.br/alimentos/appcc.htm>. Acesso em: 04 out. 2008.

ALIMENTOS próprios para cada animal de estimação. Disponível em: <http://www. petbrasil.com.br/racao1.asp>. Acesso em: 25 jan. 2009.

ALVES, Nelson Aparecido. Utilização da ferramenta "Boas Práticas de Fabricação (BPF)" na produção de alimentos para cães e gatos. 2003. 107 f. Dissertação (Mestrado em Engenharia Agrícola) - Universidade Estadual de Campinas, Campinas.

BRASIL. Ministério da Agricultura, Pecuária e Abastecimento. Instrução Normativa No. 1, de 13 de fevereiro de 2003. Aprova o Regulamento Técnico sobre as Condições Higiênico-Sanitárias e de Boas Práticas de Fabricação para Estabelecimentos Fabricantes e Industrializadores de Alimentos para Animais e o Roteiro de Inspeção. Diário Oficial da União, Brasília, DF, 28 fev. 2003 a.

Ministério da Agricultura, Pecuária e Abastecimento. Instrução Normativa $\mathrm{N}^{\circ} .15$, de 29 de out. de 2003. Aprova o Regulamento Técnico sobre as Condições Higiênico-Sanitárias e de Boas Práticas de Fabricação para Estabelecimentos que Processam Resíduos de Animais Destinados à Alimentação Animal, o Modelo do Documento Comercial e o Roteiro de Inspeção das Boas Práticas de Fabricação. Diário Oficial da União, Brasília, DF, 30 out. 2003 b. 
Ministério da Agricultura, Pecuária e Abastecimento. Circular №. 175, de 16 de maio de 2005. Procedimentos de Verificação dos Programas de Autocontrole. Diário Oficial da União, Brasília, DF, 16 maio 2005

Ministério da Agricultura, Pecuária e Abastecimento. Instrução Normativa $\mathrm{N}^{\circ}$. 4, de 23 de fevereiro de 2007. Aprova o Regulamento Técnico sobre as Condições Higiênico-Sanitárias e de Boas Práticas de Fabricação para Estabelecimentos Fabricantes de Produtos Destinados à Alimentação Animal e o Roteiro de Inspeção. Diário Oficial da União, Brasília, DF, 1 mar. 2007.

Ministério da Agricultura, Pecuária e Abastecimento. Instrução Normativa Nº. 17, de 07 de abril de 2008. Proíbe em todo território nacional a fabricação, na mesma planta de produtos destinados à alimentação de ruminantes e de não-ruminantes, exceto os estabelecimentos que atenderem aos requisitos estipulados. Diário Oficial da União, Brasília, DF, 08 abril 2008.

Ministério da Agricultura, Pecuária e Abastecimento. Portaria №. 368, de 04 de setembro de 1997. Regulamento Técnico sobre "Condições Higiênico-Sanitárias e de Boas Práticas de Fabricação para Estabelecimentos Elaboradores/Industrializadores de Alimentos". Diário Oficial da União, Brasília, DF, 8 set.1997. Disponível em:< http:// extranet.agricultura.gov.br/sislegis-consulta/consultarLegislacao.do?operacao=visualiza r\&id=3015>. Acesso em: 16 out. 2009.

Ministério da Agricultura, Pecuária e Abastecimento. Resolução Mercosul №. 80, de 11 de outubro de 1996. Regulamento Técnico do Mercosul sobre as Condições Higiênico-Sanitárias e de Boas Práticas de Fabricação para Estabelecimentos Elaboradores/Industrializadores de Alimentos".. Disponível em: <http://extranet. agricultura.gov.br/sislegis-consulta/consultarLegislacao.do?org.apache.struts.taglib. html>. Acesso em: 01 fev. 2010.

CANTO, Alfredo Portela do. Por que e para que foi criado o cGMP? Disponível em: $<$ http://www.banasqualidade.com.br/textos.asp?codigo=4580 . Acesso em: 27 jan, 2009.

FRANÇA, José Edson. Duas novas empresas conquistam a certificação de qualidade PIQ PET. Disponível em: <http://anfalpet.org.br/Site/newslettervisualizacao. php?idnews=162 >. Acesso em: 28 jan. 2010.

LOTURCO, Roseli. O custo pet. Revista Você S/A, São Paulo, n.136, p.84-85, out. 2009.

MICHALCZYSZYN, Micheli et al. Avaliação e certificação em Boas Práticas de Fabricação de uma empresa de alimentos orgânicos no município de Ponta Grossa, PR - estudo de caso. Revista Higiene Alimentar, v.22, n.159, p.33-35, mar. 2008. 
NASCIMENTO, Giuliano Alencastre do; BARBOSA, Juliana dos Santos. BPF - Boas

Práticas de Fabricação: Uma revisão. Revista Higiene Alimentar, v.21, n.148, p. 24-30, jan.-fev. 2007.

RAMOS, Rosélia Zazycky; CUNHA, Maria da Graça Alves; SCHMIDTH, Verônica. Boas Práticas de Fabricação em indústria de panificação: relato de caso. Revista Higiene Alimentar, v.19, n.137, p.34-38, nov.-dez. 2005.

SETOR de pet food tem crescimento zero em 2008. Revista feed\&food, São Paulo, v.3, n.23, p.76, dez. 2008- jan.2009.

SETOR de pet food (alimentos para animais de companhia) teve crescimento negativo em 2008. Disponível em: <http://anfalpet.org.br/site/principal.php?id_menu=6. > Acesso em: 24 abril 2009.

TAYLOR, Jessica. Top Global Petfood Leaders. 2009. Disponível em: <http://www. petfoodindustry-digital.com/petfoodindustry/200901/templates/pageviewer_ print?pg24\&pm>. Acesso em: 5 fev. 2009.

TOMICH, Renata Graça Pinto et al. Metodologia para avaliação das boas práticas de fabricação em indústrias de pão de queijo. Ciência e Tecnologia Alimentar, vol.25, n.1, p. 115-120. jan-mar. 2005. Disponível em: <www.scielo.br/scielo.php?=s010120612005000100019\&script=sci_pdf\&tlng=pt>. Acesso em: 14 ago. 2009.

VERSIGNASSI, Alexandre et al. Humano. Revista Superinteressante, São Paulo, n.263, p.54-63, mar. 2009.

WINCKLER, Marili Gramolini Garcia. Evolução dos pré-requisitos, Boas Práticas de Fabricação (BPF) e Procedimento Padrão de Higiene Operacional (PPHO), em Matadouro-Frigorífico de bovinos, localizado no município de Rondonópolis, MT, no período de março a outubro de 2004. Revista Higiene Alimentar, v.21, n. 155, p.48-51, out. 2007. 


\section{SOBRE O(S) AUTOR(ES)}

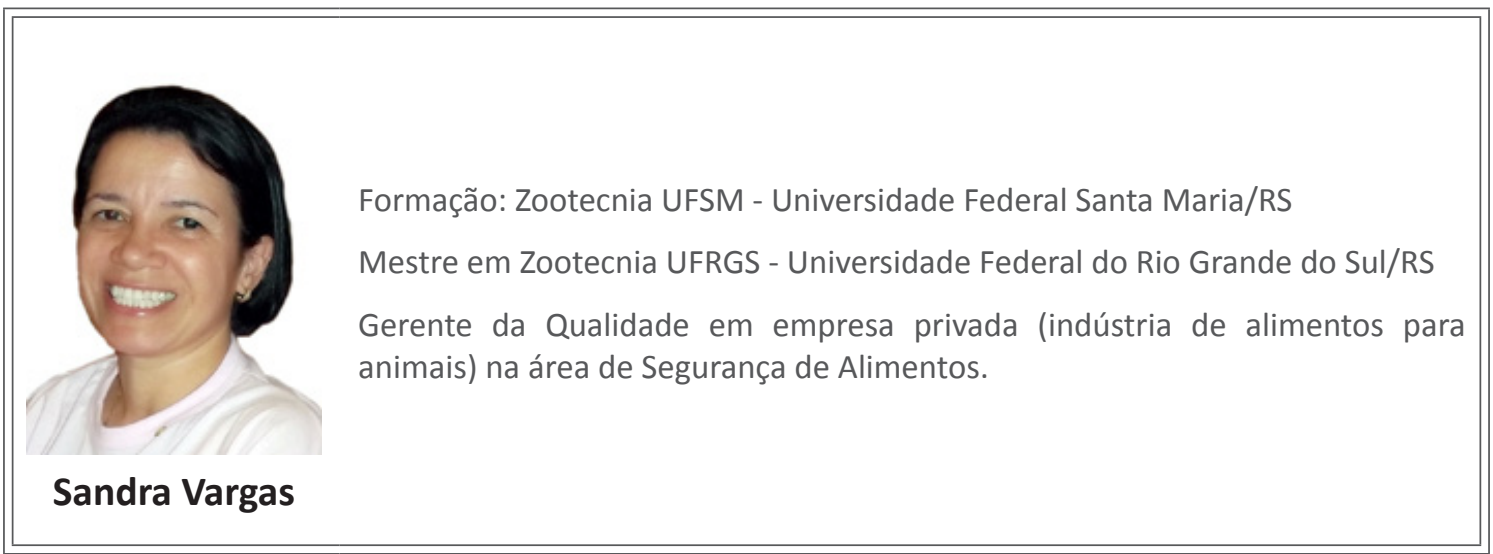

\begin{tabular}{|l} 
Médica Veterinária graduada pela Universidade Federal de Uberlândia (UFU) \\
e mestra em Ciência de Alimentos pela Universidad Autonoma de Barcelona \\
(UAB), Espanha. \\
É Lead Assessor na ISO 9001, consultora e multiplicadora do Programa Alimentos \\
Seguros (PAS) - Setor Indústria. \\
Atuou como instrutora e consultora do SENAI SC em Florianópolis para \\
implantação de Sistemas de Gestão para a Segurança de Alimentos. Foi \\
coordenadora e docente do curso de Pós-Graduação MBA em Gestão para \\
Segurança de Alimentos a distância e trabalhou na implementação e em \\
auditorias internas de Sistemas de Gestão de Qualidade e de Segurança de \\
Alimentos em diversas indústrias da área. Autora do livro Sistemas de Gestão de \\
Segurança de Alimentos, em 2008, publicado pelo SENAl e do livro Sistema de \\
Qualidade em Segurança de Alimentos: ABNT NBR ISO 22000:2006, Eurepgap \\
e BRC, publicado em 2007, pelo SENAI. Foi consultora da Organização Pan- \\
Americana da Saúde (OPAS/ OMS) em 2000-2001. \\
Atualmente é Coordenadora da Rede SENAI/SC de Educação a Distância.
\end{tabular}

